\title{
Primary School Teachers' Conceptions of Classroom Assessment: A Qualitative Study
}

\author{
Sethusha Mantsose Jane \\ Department of Teacher Education, University of South Africa
}

\begin{abstract}
This article explored conceptions that primary school teachers hold about classroom assessment and how these conceptions influence their classroom assessment practices. The study was qualitative in nature and employed an instrumental case study approach. Semi-structured interviews, observations and document analyses were used. The study utilized Brown's [4] conceptual framework on conceptions of assessment. The findings reveal that teachers' conceptions of assessment are influenced by the social and education context in which they find themselves and that their personal experiences of assessment also influence their conceptions of assessment.
\end{abstract}

\section{Introduction}

Understanding and communicating assessment related information has been highlighted as a crucial component of teacher professional development needs (Harris and Brown) [15]. This implies that understanding teachers' beliefs about assessment is critical in designing and implementing appropriate teacher professional development. Irrespective of their level of experience and competence, teachers make what seem to them rational choices and decisions that reflect their attempt to promote student learning. The dynamic quality of teachers is as a result a product of how teachers understand and conceptualize teaching, learning and assessment (Maclellan) [17]. Teaching cultures are contextually bounded and complex, so understanding and producing insight into this culture requires approaches that explore in depth teachers' reasoning about teaching, learning and assessment based on specific educational contexts and accounts of experiences within them (Akyeampong, Pryor and Ampiah[1]; Remesal [20] and Wang, Kao and Lin [24].

South Africa's post-apartheid education system, known as outcomes-based education (OBE), Curriculum 2005 (C2005), was launched in 1997. In 2007 the South African National Department of Education published the National Policy on
Assessment and Qualifications for Schools in the General Education and Training (GET) Band (Department of Education) [9]. This policy provided a framework for assessment and qualifications for all private and public schools and community based sites with learners registered in the GET band (Grade R-9). It consolidated assessment provisions contained in the National Curriculum Statement Grade R-9 (Schools) (NCS). The policy repealed the Assessment Policy in the General Education and Training Band, Grade R-9 and Adult Basic Education and Training of 1998 and the Framework for the Assessment and Promotion of Learners in Grade 9: Interim Policy, 2003. It integrated and consolidated recording and reporting provisions that are contained in the National Protocol on Assessment, 2005 (Department of Education) [9].

The National Curriculum Statement as well as the National Policy on Assessment places a strong emphasis on assessment as a major tool that teachers have to use as a vehicle for improving the quality of teaching and learning in their classrooms (Mbelani) [18]. A crucial concern is how teachers adapt their classroom assessment practices to comply with the demands made by the curriculum, assessment guidelines and assessment policy. Since the introduction of outcomes based education in South Africa, teachers have been exposed to trends in assessment through cluster workshops, in-service and pre-service training and an abundant supply of curriculum documents, all with the aim of fasttracking transformation and improving quality teaching and learning. However, my experience is that little has improved inside the classroom. It therefore remains important to understand how teachers understand and practice assessment. This article is therefore designed to investigate teachers' conceptualization of classroom assessment and how these conceptions influence their classroom assessment practices.

The National Policy on Assessment and Qualifications for Schools in the GET Band (Department of Education) [9] clearly stipulates that assessment is an integral part of teaching and learning where the teacher has to meet diverse needs of learners in the classroom. This is a challenge in the sense that as designers of the curriculum, 
teachers are expected to understand policies, so as to meet the needs of the learners. If teachers are required to understand learners' diverse needs, their conceptions and understanding of different policies are also equally important. Only then will they be able to engage in practices that will improve the whole process of teaching and learning.

\section{Conceptual Framework}

This article utilizes the conceptual framework based on the work of Brown [4]. In this conversation, four major conceptions about assessment are exhibited; (1) assessment is related to improvement of learners' learning and teachers' teaching, (2) assessment certifies that learners have learned or met standards, (3) assessment evaluates the quality of schools and teachers, and (4) assessment is irrelevant to the work of teachers.

Based on the literature reviewed (Brown) [2-5], (Harris and Brown) [15] and (Brown and Harris) [67] the four major conceptions are used as filters through which teachers interpret and experience state sponsored or school-wide policies and practices related to assessment. It is appropriate to investigate how teachers conceive of assessment and how their different conceptions influence their classroom assessment practices in order to get a fuller understanding of what assessment means to teachers in a South African context.

\section{Research method}

The research was conducted in two primary schools in one city in South Africa. I focused on two grades (grade 5 and 6) in the intermediate phase, which comprises of Grade 4, 56 and 7.

In this article I focus on two primary school teachers and use a variety of data including in-depth semi-structured interviews, classroom observations and analysis of key documents (learners' books, teachers' assessment documents. The interview schedule comprised of questions on teachers' own understanding and experiences of classroom assessment. Observations of teaching and assessment practices were conducted over a four-week period with each teacher. The observations were followed by interviews and these provided teachers with an opportunity to share their understanding and experiences.

\section{Research Findings}

\subsection{Understanding teachers' conceptions of assessment}

\section{Case study one}

Alice Evans "Assessment is my most important focus because it guides me and the learners as well; it tells us where we are and where we aren't, where we are okay and where we have problems"

Alice has been teaching at Eastridge Primary school since 1985. She started her teaching career at this school as a temporary teacher. She has a teachers' diploma that focused on teaching methodologies and a degree. Her teacher training encompassed the basics of learning how to teach, with a specialization in English with assessment mainly on giving examples of theories, on examinations and on teaching practice evaluation. During these teaching practices, lecturers would visit them to evaluate how they taught. Alice referred to these visits as 'crit' lessons, as they were called in those years. She did not like these visits:

"To me when I look back, it was very judgmental. In fact, it was not assessment; it was called evaluation and emphasized class tests and examinations. This evaluation relied a lot on the lecturer's personal judgment, what they know, how they know and how they look at a particular aspect of teaching. I think that has changed tremendously now, how we look at teaching has changed, we are far more objective now”.

During her teacher training years, Alice did not get any training on assessment. She gained much assessment knowledge from in-service training in OBE in 2002 and 2003, organized by a teachers' union. Assessment was not the only aspect dealt with in these trainings, but it was emphasized as most teachers were experiencing difficulties in understanding and implementing Outcomes Based Assessment (OBA). Alice also attended a workshop at the beginning of 2009, where one departmental official addressed issues relating to assessment.

Alice felt that her training needs were mainly related to assessment, which she wished to have more guidance on how to conduct. For her, assessment was;

“... something that you need to plan for and need to work through all the time. I don't think most of our teachers understand that assessment is a well thought of process, you cannot work out marks and submit to your Head of Department, it must be thought of beforehand".

Alice identified fully with the principles of the NCS, and seemed eager to learn as much as possible about these and translate them into her classroom practice. She portrayed a good understanding of the 
curriculum, the NCS, and assessment policy. She was very vocal about the value and benefit of these, convinced that they could yield better results for the school. She also seemed to utilize every opportunity to learn more about the NCS and its Assessment Guidelines. For example, during the interview, she highlighted that she took it upon herself to look out for any assessment information, be it from workshops, clusters or district officials.

Alice expressed her understanding of assessment as follows:

"I would say assessment is a way of determining where children are in terms of what has been taught, first of all where they are now and then, also to see how much they grasped of what has been done. So it gives you as the teacher direction of where they are, what knowledge they have acquired, and that guides you as to what you still need to do. In other words um... you assess to see what they have gained and how far they have progressed along the way".

Her understanding was in line with the definition of assessment stipulated in the NCS Assessment Guidelines for the GET Band (Department of Education) [9], which are part of a developmental process aimed at increasing the capacity of the South African education system, teachers, school management teams and the departmental officials. These guidelines aim to enhance the effective implementation of this by developing an authentic assessment system that is congruent with OBE in general and the NCS in particular (Department of Education) [9].

The NCS assessment guidelines define assessment as:

... a process of making decisions about a learner's performance. It involves gathering and organizing of information (evidence of learning) in order to review what learners have achieved. It informs decision making in education, and helps teachers to establish whether learners are performing according to their full potential and making progress towards the required levels of performance (or standards) as outlined in the Assessment Standards of the NCS (Department of Education) [9].

Although the policy indicates how assessment needs to be fair, reliable and valid, recent research by Vandeyar and Killen [22] documents an inability or unwillingness of many South African teachers to adapt their assessment practices to the changing demands of the country's school education. Alice was very clear in her mind and in her articulation of her understanding of the assessment policy that the policy was a guideline, a frame of reference for assisting teachers in executing their tasks:

"The learning area specialist once came to our school to check on our assessment. She gave us a quiz, to check as to whether our assessments were valid, fair and reliable. She requested us to use an assessment task that we once did in class. I was very happy at the end of the exercise when she told us that my quiz as well as another teachers' quiz in my department were the best".

As can be inferred, Alice was very optimistic and enthusiastic about the possibilities of the underlying NCS assessment key principles, that assessment is concerned with issues of reliability and fairness. Assessment is conducive to reliability in that learning outcomes are the basis upon which assessment is planned and administered, a constant feature, regardless of who is assessing and who is being assessed. Laying down these specifications necessitates the teacher using them as a guide to planning, developing and administering assessment. Assessment tasks are regarded as fair and free from bias when they are equally good measures for learners of different linguistics, gender, culture and socio-economic groups present in the school population. This also refers to learners having equivalent resources with which to perform the task, at home or at school, and having an equal opportunity to learn.

Alice identified a number of factors that hindered her assessment practices. She noted with great concern of the amount of paper work involved in assessment, which as Head of Department (HoD) she was worried that most teachers strive to complete rather than helping learners to achieve the learning outcomes and meet the assessment standards. She indicated that in the Home Language (English) learning area, a teacher is required to assess learners in all learning outcomes, namely listening, speaking, reading and viewing, writing, thinking and reasoning, and language structure and use, and to compile assessment tasks that include more than one assessment standard. The Home Language assessment standards assume that learners are able to read, understand and speak the language taken at Home Language level. These assessment standards support the development of these competencies, especially with regard to various types of literacy, notably reading, writing, and visual (also regarded as critical) literacies.

According to Alice, assessment consumed most of her teaching time because she believed in providing learners with ample opportunities to achieve the learning outcomes. She believed it was an opportunity to get to know her learners even better, on a personal level. Most of the time teachers concentrate on completing the work and recording, 
without paying extra attention to learners who are struggling to achieve. Alice was proud to mention that a learning area specialist for English once visited her, to give her support as $\mathrm{HoD}$, and was very impressed with her work.

Alice's understanding of the rationale behind provision of expanded opportunities for learners is consistent with the policy as it highlights that learners must be given an opportunity to learn at a varied pace so as to achieve learning outcomes and assessment standards. Expanded opportunity is one of the principles of Outcomes Based Assessment. This principle requires that teachers find multiple ways of exposing learners to opportunities that will enable them to demonstrate their full potential. Learners are expected to succeed, but not necessarily at the same time and in the same way. The teacher needs to maximize opportunities for every learner by challenging them to achieve and improve as individuals, but not to compete against other learners (Department of Edcuaction) [9].

On the question of the difference between the current way of assessing and the one used in the previous old curriculum, Alice said that:

"It is very different. In the past we just wrote tests and exams, we were not given any hint of what to study, and how we would be assessed. Again... it was in the form of marks, like ten out of ten. Of course when you got ten out of ten we understood it to mean that you did extremely well".

As Alice posits, her assessment practices were very different from those used to assess her at school and during her training. During one of my classroom observations, I noticed that when she assessed reading she let the children read, whilst listening to their pronunciation and fluency, how they paid attention to reading signs and how they changed their tones. She used a rubric to assess reading, and gave them feedback with comments for improvement. Reflecting on her schooling she said "In the past, teachers used to ask us to read and just award marks on whether you could read or not”.

Assessment of reading is now formal, fair and less subjective. Reading is very important because it prepares learners for writing. When Alice felt that learners had read enough she gave them a spelling test. She was very strict with spelling, and when a learner missed one letter in a word she marked it as wrong:

"I've heard other teachers saying in content subjects like Arts and Culture, Social Studies and Life Orientation ....as long as the child has got an idea of a word, even when they have missed a letter, they mark it as right. I do not like that at all. It gives learners an impression that correct spelling is acceptable in Languages and not in content subjects".

Alice indicated in the interview that during her schooling years they were encouraged to spell correctly, irrespective of whether they were in a History, Mathematics or Language class. Her previous experiences influenced her present practices in classroom assessment. She encouraged her colleagues to pay attention to spelling across all learning areas because she believed it was the right thing to do.

Alice's understanding of assessment appeared to be firmly rooted in her interpretation of the NCS policy and assessment guidelines. The NCS, the National Policy on Assessment and the NCS Assessment Guidelines were the only sources that Alice consulted, and as such were initially assumed to have played a more significant role on her understanding of assessment. Her understanding was also embedded in the assessment knowledge and experience that she had acquired over the course of her teaching life, particularly in her role as HoD in the school. It also appeared that Alice agreed with the conception that assessment improved teaching and learning. Alice believed that the purpose of assessment was to inform learners where they stood as compared to their peers as well as to identify their weaknesses and strengths. Alice interpreted assessment as increasing the workload of teachers, as it required much paperwork and extra preparation time.

In summary, Alice conceptualized classroom assessment in the following major ways: as a tool to improve teaching and learning; as providing information on how well teachers were doing their work; as a means of teacher and learner reflection; and as a means to check learner progress against achievement objectives.

\section{Case study two}

Roshnee Rajesh “I assess the learners' abilities holistically, to determine their competencies and achievement of learning outcomes"

Roshnee Rajesh was in her eleventh year of teaching and was the deputy principal of Windyside primary school. She started teaching at this school in April 2009, having been a teacher at another school in the district, where she taught English to Grades 4, 5 and 6. Roshnee obtained a diploma in Adult Education and Training in 1994 and a degree in Education from the University of Durban Westville in 1998. At the time of this research she was still studying for a degree in Human Resource Development. She was a full-time teacher, but in between had spread herself out through adult education and teaching at different schools. She has 
been involved in a number of adult facilitation activities. Roshnee was an accredited assessor and moderator. She studied privately for this certificate in 2007 and also trained as an asset manager in the same year. The assessor training was scheduled for a week and they were expected to compile a portfolio, as part of their assessment. The assessor training was conducted by a non-governmental organization (NGO) known as International Competencies Network.

The idea of imparting new knowledge, as well as interaction with learners, had motivated Roshnee to follow a teaching career, despite the fact that there was much pressure as well. She sounded positive and committed towards working hard:

"I really think there is a lot of pressure on teachers in terms of curricula, assessment and teaching generally. So you have to be able to stand up to it and be ready for the challenges".

She did not receive any training specifically on assessment but such training was incorporated into the NCS training that the DoE offered for a week in 2005.

Roshnee's views on what she understood by classroom assessment were expressed as follows:

"I would say I assess the learners' abilities holistically, what the learners' competencies are and to see if basically they have met outcomes as set per term by the Department of Education for each learning area. A child has to be able to accomplish something at the end of each year or each term and you basically use the correct means to see if the child is able to meet those goals".

In providing her understanding of classroom assessment, Roshnee referred to the purpose of assessment, which was in line with the NCS Assessment Guidelines in that she highlighted "assessing learners' abilities and competencies holistically", implying that teachers had to establish whether learners were performing according to their full potential. Roshnee was aware that she should use different methods to assess learners, as was evident in her expression of "using the correct means" in her understanding of assessment.

According to Roshnee, the assessment policy was streamlined and more prescriptive, but there were still loopholes. Her major concern was with support and the direction that teachers needed from the DoE. She felt if those could be addressed it would make life easier for her, especially with the introduction of the milestones. According to the Foundation For Learning Campaign (FFLC), milestones referred to the knowledge and skills from Learning Outcomes and Assessment Standards for Mathematics and
Languages per term and per grade to all schools (DoE, 2008). Roshnee felt that she still needed clearer guidelines on these milestones, as well as much more prescriptive ideas on how she could work with the FFLC.

Roshnee provided me with a copy of the milestones. For the third term those identified were oral, reading, writing, spelling and grammar and investigation. For each milestone there were standards suggested for accomplishing the milestones. At the end was the final rating, indicating the level of achievement for them.

Based on the information provided by Roshnee in the interview, teachers under her supervision did not really have a clear understanding of the assessment policy or its guidelines. She felt teachers still needed much training and workshops on assessment. Roshnee thought much assessment in her school did not probe the deeper thinking processes of the learners expected by Bloom's taxonomy, and as a result children did not develop complex thinking skills, and were unable to synthesize, analyze or evaluate. According to Roshnee, children might be able to recall and best apply information but they could not go into the deeper levels of thinking. As a deputy principal, she had observed that the questions that some teachers set in their assessment tasks did not probe learners' thinking and did not take them to a higher level. She felt teachers needed to attend workshops on assessment, especially on how to implement proper questioning techniques. Her personal feeling was that this needed to be done by somebody with experience of the classroom, the $\mathrm{HoD}$, an SMT member or mentoring teacher. She indicated that before learners wrote the examination in the second term, she requested teachers to send her their examination papers once the HODs had checked them. That was for her to ascertain the assessment level. She found that there were some learning areas where the questioning needed to be upgraded, and felt that the learners' thinking processes could be probed further. However, this was not happening. She found some tasks to be at the level of the learners, but were too simplistic.

Teachers in her school needed to move away from the old school of thought, that of relying on tests as the best way to assess. Her approach was that learners had to be looked at holistically, that it was important for teachers to look at what the learners' competencies were, and to base their assessment on that. Roshnee also understood that different preferences of learners had to be taken into consideration in assessment:

"There are children who are more inclined towards practical tasks and those who are actually good at writing things down. A teacher needs to get a good balance in the forms of assessment to be used as well as how to use different tools effectively, like the 
rubrics and checklists and not only to rely on tests and memoranda".

Her understanding was that with assessment it should not only assess where the learners are at that particular moment, but should allow the learner to think laterally, to engage in lateral and critical thinking.

The current way of assessing learners, as Roshnee posits, was making a difference in the way learners were taught:

"If teachers assess the way they are supposed to, then they would get a much clearer picture of the holistic competencies of learners. I think previously the focus was more on the learners' ability to read and write and that was it. Now we are giving learners an opportunity to investigate and do. I think we are finding that the results are much better. If assessment techniques are used correctly then assessment results would be interpreted correctly".

Roshnee displayed a clear understanding of the Foundations for Learning Campaign, as she referred to the FFLC milestones, and how she incorporated them into her lessons and in her assessments, as well as for the National Policy on Assessment and the NCS assessment guidelines.

Roshnee's conceptualizations of classroom assessment can be summarized as being that assessment determines how much learners have learned, helps in improving teaching and learning, identifies barriers to learning as well as learners' strengths and weaknesses,

\section{Discussion and Conclusion}

The two teachers' conceptions were mostly influenced by their beliefs (Eren) [11]. They believed assessment was mainly intended for improvement of teaching and learning and for school accountability, hence their practices reflected these two conceptions. Findings from this study confirmed what several researchers have argued, that teachers held strong beliefs which influenced their conceptions (Korthagen [16]; Calderhead [8] and Pendry [19]). The most significant contributions of research in education suggest that teachers' beliefs relate to their classroom practice (Gonzales and Fuggan) [13]. According to Good and Brophy [14], Dixon and Haigh [10] and Gipps and Brown [12] a better understanding of teachers' belief system or conceptual base significantly contributes to enhancing educational effectiveness. Based on the evidence gleaned from the study, I posit that to understand assessment from the teachers' perspectives it is necessary to understand the beliefs with which they define their work. The beliefs teachers held influenced their perceptions and judgments (Susuwele-Banda) [21], which in turn affected their behavior in the classroom. The interaction of beliefs and practices therefore had strong implications for teaching and learning (Verdar) [23]. Furthermore, I posit that this type of interaction is critical for any in-service programme.

Calderhead [8] highlights the important role that personal history plays in shaping the teachers' conceptions about classroom assessment. It is evident from the findings that teachers constructed their own understanding of assessment, based on their experiences. Alice and Roshnee had developed a wealth of knowledge and experience, gathered from a life-time exposure to training, workshops and exposure to the curriculum.

I argue that the evidence gleaned from this research suggests that Alice and Roshnee have different conceptions that could be mapped onto the four major conceptions as outlined by Brown [6]. They also conducted assessment to comply with requirements, and they included practices that went against their personal beliefs. Assessment for improvement was regarded as the major conception.

Alice and Roshnee conceptualized assessment as focusing on individualistic teaching and learning rather than catering for the needs of the whole group. What this paper shows is also that teachers' conceptions of assessment are affected by multiple pressures. These include pressures such as compliance, time management, policy interpretation and implementation, extra administrative workload and paperwork, support from the departmental officials and training. As Harris and Brown [15] discovered, these multiple tensions create a much more complex teaching thinking space than the simple dichotomy.

Notwithstanding the data from these two teachers from culturally different environments, the pattern of conceptions revealed is consistent with previous studies with teachers in different phases and levels of schooling, and in different learning areas. However, the most important point to be made here is that, from the data, more focus was on the improvement and school accountability conceptions and less on student accountability and irrelevance.

This article has shown that teachers see assessment as having a range of diverse purposes, and different assessment practices are seen as being aligned with these purposes. While assessment clearly has a range of purposes, it is important that teachers are enabled to move beyond compliance, so that they can actually make educational use of data they collect, which is the valid role of assessment. 


\section{References}

[1] Akyeampong, K., Pryor, J. and Ampiah, J.G., (2006). A vision of successful schooling: Ghanian teachers' understanding of learning, teaching and assessment. Comparative Education, (42) 2, 155176.

[2] Brown, G.T.L., and Hirschfeld, G.H.F., (2008). Students' conceptions of assessment: Links to outcomes Assessment in Education: Principles, Policy and Practice, (15) 1, 3-17.

[3] Brown, G.T.L., (2003). Teachers’ instructional conceptions: Assessments' relationship to learning, teaching, curriculum and teacher efficacy. Paper presented at the joint conference of the Australian and New Zealand Associations for Research in Education (AARE/NZARE), Auckland, 28 Nov. - 3 Dec.

[4] Brown, G.T.L. (2004). Teachers' Conceptions of Assessment Implications for Policy and Professional Development. Assessment in Education: Principles, Policy and Practice, (11) 3, 301-318.

[5] Brown, G.T.L., (2006). Queensland Teachers' Conceptions of Teacher, Learning, Curriculum and Assessment, Comparisons with New Zealand teachers. Paper for Engaging Pedagogies, the Annual Conference of the Australian Assessment for Research in Education (AARE) Adelaide.

[6] Brown,G.T.L., and Harris, L.R., (2010). Teachers' Enacted Curriculum: Understanding Teacher Beliefs and Practices of Classroom Assessment. International Association for Education Assessment Annual Conference, Bangkok, Thailand.

[7] Brown, G. T. L., Harris, L. R., O’Quinn, C., and Lane, K. E., (2011). New Zealand and Louisiana practicing teachers' conceptions of feedback: Impact of Assessment of Learning versus Assessment for Learning policies. Paper presented to the Classroom Assessment SIG at the annual meeting of the American Educational Research Association, New Orleans, LA.

[8] Calderhead, J., (1996). Teachers: beliefs and knowledge. In Berliner, D \& Calfree, R (Eds.), Handbook of educational psychology, 709-725, New York: Macmillan.

[9] Department of Education, (2007). National Policy on Assessment and Qualifications for Schools in the General Education and Training Band. Government Gazette, 500 (29626). Pretoria.
[10] Dixon, H., and Haigh, M., (2008). Changing Mathematics teachers' conceptions of assessment and feedback. Teacher Development, Routledge Taylor Francis Group, (13) 2, 173-186.

[11] Eren, A., (2010). Consonance and Dissonnance between Turkish prospective teachers' values and practices: Conceptions about teaching, learning and assessment. Australian Journal of Teacher Education, (35) 3.

[12] Gipps, C., Brown, M., McCallum, B and McAlister, S., (1995). Intuition or evidence? Teachers and national assessment of seven-year-olds. Buckingham, UK: Open University Press.

[13] Gonzales R., and Fuggan C.G., (2012). Exploring the Conceptual and Psychometric Properties of Classroom Assessment. The International Journal of Educational and Psychological Assessment. (9) 2.

[14] Good, T.L., and Brophy, J.E., (2003). Looking in classrooms (9th ed.). Boston: Allyn and Bacon.

[15] Harris, L., and Brown, G.T.L., (2008). New Zealand teachers' conceptions of the purpose of assessment: Phenomenographic analyses of teachers' thinking. Paper presented to the Australian Association for Research in Education (AARE) Annual Conference, Brisbane, Australia.

[16] Korthagen, F.A.J., (1993). Two modes of reflection. Teaching and Teacher Education, 9, 317326.

[17] Maclellan, E., (2001). Assessment for learning: the differing perceptions of tutors and students. Assessment \& Evaluation in Higher Education, (26) 4.

[18] Mbelani, M., (2008). Winds of change in teachers' classroom assessment practice. A selfcritical reflection on the teaching and learning of visual literacy in rural Eastern Cape High school. English Teaching: Practice and critique. (7) 3, 100114. Rhodes University.

[19] Pendry, A., (1997). The pedagogical thinking and learning of history student teachers. In McIntyre, D. (Ed.) Teacher Education: Research in a new context, 76-78. London: Paul Chapman.

[20] Remesal, A., (2011). Primary and Secondary Teachers' Conceptions of assessment: A Qualitative Study, Teaching and Teacher Education, Elsevier, (27) 2, 472-482. 
[21] Susuwele-Banda W.J., (2005). Classroom Assessment in Malawi: Teachers' perceptions and Practices in Mathematics. PhD thesis, Blacksburg, Virginia.

[22] Vandeyar, S., and Killen, R., (2007). Educators' conceptions and practice of classroom assessment in post-apartheid South Africa. Journal of Education, 27: 101-115.

[23] Verdar, E., (2010). Sixth, Seventh and Eighth Grade Teachers' Conception of Assessment. Msc Thesis. Graduate School of Social Sciences of Middle East Technical University

[24] Wang, J.R., Kao H.L., and Lin S.W., (2010). Pre-service teachers' initial conceptions about assessment of science learning: The coherence with their views of learning science. Graduate Institute of Mathematics and Science Education. National Pingtung University of Education, Taiwan. 